\title{
ANALISIS SISTEM PENGEMBANGAN SUMBER DAYA MANUSIA DI LEMBAGA KEUANGAN MIKRO SYARIAH
}

\section{ANALYSIS OF HUMAN RESOURCE DEVELOPMENT SYSTEM IN MICRO SHARIA FINANCIAL INSTITUTIONS}

\author{
M. Paramita ${ }^{1}$ \\ 1Program Studi Ekonomi Islam Fakultas Ekonomi Islam Universitas Djuanda, Jl. Tol Ciawi \\ No. 1, Kotak Pos 35 Bogor 16720
}

\begin{abstract}
This study aims to determine the system of human resource development in five Sharia Micro Finance Institutions namely BMT Berkah Mandiri Sejahtera, KSPPS Berkah Bersama, BMT Binaul Ummah, KBMT Tadbiirul Ummah, dan Baytul Ikhtiar. The method used is descriptive qualitative. Primary data in this research are observation and depth interview. Based on the result of the research, it is concluded that in several Sharia Micro Finance Institutions, namely BMT Berkah Mandiri Sejahtera, KSPPS Blessing Bersama, BMT Binaul Ummah, KBMT Tadbiirul Ummah, Cooperative of Baytul Ikhtiar has implemented development system for Human Resources so that there is improvement in terms of skill, knowledge and good attitudes, the statement is reinforced by employee performance indicators, the work of each employee and some support programs of training and development undertaken by all employees owned by each LKMS.
\end{abstract}

Keywords: Development System, Human Resources, BMT, KSPPS

\begin{abstract}
ABSTRAK
Penelitian ini bertujuan untuk mengetahui sistem pengembangan Sumber Daya Manusia (SDM) pada lima Lembaga Keuangan Mikro Syariah yaitu BMT Berkah Mandiri Sejahtera, KSPPS Berkah Bersama, BMT Binaul Ummah, KBMT Tadbiirul Ummah, Koperasi Baytul Ikhtiar. Metode yang digunakan yaitu deskriptif kualitatif. Data primer pada penelitian ini berupa observasi dan wawancara mendalam. Berdasarkan hasil penelitian, disimpulkan bahwa pada beberapa Lembaga Keuangan Mikro Syariah yaitu BMT Berkah Mandiri Sejahtera, KSPPS Berkah Bersama, BMT Binaul Ummah, KBMT Tadbiirul Ummah, Koperasi Baytul Ikhtiar telah melaksanakan sistem pengembangan untuk Sumber Daya Manusia agar ada peningkatan dari segi keterampilan, pengetahuan dan sikap yang baik, pernyataan tersebut diperkuat dengan indikator kinerja karyawan, hasil kerja setiap karyawan dan beberapa program pendukung yaitu pelatihan dan pengembangan yang dilakukan oleh semua karyawan yang dimiliki oleh setiap LKMS.
\end{abstract}

Kata kunci: Sistem Pengembangan, Sumber Daya Manusia, BMT, KSPPS

Paramita, Metti. 2017. Analisis Sistem Pengembangan Sumber Daya Manusia di Lembaga Keuangan Mikro Syariah. Jurnal Syarikah 3 (2): 343 - 357 


\section{PENDAHULUAN}

Keberadaan Lembaga Keuangan Mikro Syariah (LKMS) saat ini dimaksudkan untuk mengembangkan usaha produktif dan investasi masyarakat kecil berdasarkan prinsip syariah yang tidak tersentuh oleh lembaga perbankan. Jumlah LKMS (termasuk di dalamnya BMT) di Indonesia selalu mengalami kenaikan dari tahun ke tahun, tahun 2004 terdapat 3000 BMT, tahun 2006 sebanyak 3200 BMT, dan naik lagi di tahun 2010 sebanyak 5.200 BMT (Sakti: 2013). Hal ini membuktikan bahwa LKMS dapat diterima oleh masyarakat sebagai lembaga yang dapat memberdayakan masyarakat kecil.

Perkembangan LKMS tersebut sebaiknya didukung oleh faktor-faktor pendukungnya salah satunya adalah sumber daya manusia (SDM), agar kinerja LKMS semakin meningkat. Faktanya LKMS belum memiliki SDM yang berkualitas yang sesuai dengan harapan, bahkan SDM LKMS ada di bawah rata-rata professional sektor keuangan lainnya.

Profesionalisme SDM LKMS merupakan sebuah keharusan apabila LKMS ingin berkembang dan menyesuaikan dengan perubahan. Sumber daya Manusia LKMS harus memiliki kemampuan dalam mewujudkan pelayanan nasabah dengan cepat, berkualitas, dan memuaskan. LKMS diharapkan juga memiliki Sumber Daya Manusia yang senantiasa berorientasi pada peningkatan kinerja dan sekaligus meningkatkan kemampuan pelayanan, guna mewujudkan kinerja LKMS yang memuaskan, serta kesesuaian operasional lembaga dengan nilai-nilai Islami dan bisa menjadikan LKMS lebih kompetitif dengan lembaga keuangan lainnya, yang akhirnya meningkatkan kepercayaan masyarakat terhadap LKMS.

Harapan terhadap profesionalisme sumber daya manusia LKMS ini dilatarbelakangi oleh adanya kesenjangan antara kinerja yang diharapkan (intended performance) dengan kinerja nyata yang dihasilkan (actual performance). Sebagai contoh, masih banyaknya tingkat inefisiensi dalam pelaksanaan tugas merupakan bukti nyata kompetensi yang masih rendah. Sumber daya manusia yang kurang profesional cenderung akan kurang berkualitas dalam memberikan pelayanan kepada pelanggan/nasabah. Pelayanan yang tidak memuaskan tersebut akan menjadi permasalahan yang rumit, nasabah akan memilih lembaga keuangan yang lain manakala sumber daya manusia LKMS belum mampu untuk menjadi profesional dalam pelayanan dan tidak bisa beradaptasi dengan dinamika perubahan keadaan ekonomi serta kurang peka menghadapi perkembangan ilmu pengetahuan dan teknologi maka akan sulit untuk memperbaiki kinerjanya.

Dalam upaya memberikan pelayanan yang memuaskan kepada nasabah/masyarakat dan dalam rangka menjalankan operasional LKMS yang berada di daerah Bogor, sangat dibutuhkan sumber daya manusia yang memiliki kualitas yang baik agar dapat mendukung program-program LKMS. Kualitas yang handal merupakan salah satu faktor kunci yang menentukan dalam keberhasilan LKMS dalam mencapai target lembaganya. Kualitas merupakan paduan antara pengetahuan dan keterampilan dari hasil kerja secara kualitas dan kuantitas yang dapat dicapai oleh seorang pegawai dalam melaksanakan tugas sesuai dengan tanggung jawab yang diberikan kepadanya. Untuk mewujudkan hal tersebut, maka pengembangan pegawai LKMS seyogyanya harus sesuai dengan standar yang dipersyaratkan. Namun secara empiris masih banyak kualitas pegawai LKMS yang rendah. Dalam rangka peningkatan kualitas dan kemampuan (capacity building), harus didukung dengan konsep pengembangan sumber daya manusia.

\section{MATERI DAN METODE}

\section{Pengembangan Sumber Daya Manusia}

Tujuan pengembangan SDM adalah untuk memperbaiki efektifitas dan 
produktivitas kerja dalam melaksanakan dan mencapai sasaran yang telah ditetapkan. Pengembangan SDM dalam suatu LKMS sangat diperlukan sampai pada taraf tertentu sesuai dengan pengembangan organisasi. Apabila LKMS ingin berkembang seyogyanya diikuti oleh pengembangan SDM, pengembangan SDM ini dapat dilaksanakan melalui pendidikan dan pelatihan, terutama untuk pengembangan intelektual dan kepribadian. Pendidikan pada umumnya berkaitan dengan mempersiapkan SDM yang digunakan oleh organisasi, sedangkan pelatihan dimaksudkan untuk mempertahankan dan memperbaiki prestasi kerja yanag sedang berjalan serta berusaha untuk mengembangkan keterampilan di masa yang akan datang.

Adapun pengertian pengembangan menurut para ahli adalah sebagai berikut (Rivai, 2009 : 298) :

Menurut Mangkunegara (2005) pengembangan merupakan suatu proses pendidikan jangka panjang yang mempergunakan prosedur sistematis dan terorganisasi di mana pegawai manajerial mempelajari pengetahuan konseptual dan teoritis guna mencapai tujuan yang umum.

Menurut T Hani Handoko (2002) pengembangan (development) mempunyai ruang lingkup lebih luas dalam upaya untuk memperbaiki dan meningkatkan pengetahuan, kemampuan, sikap, dan sifatsifat kepribadian. Pengembangan menyiapkan para karyawan untuk melakukan pekerjaan-pekerjaan di waktu yang akan datang.

Dengan demikian pengembangan adalah usaha yang sistematis untuk meningkatkan kemampuan sumber daya manusia melalui pendidikan dan pelatihan untuk kepentingan saat ini dan jangka panjang.

\section{Konsep Dasar Lembaga Keuangan Mikro Syariah (LKMS)}

Secara konsepsi LKMS adalah suatu lembaga yang didalamnya mencakup dua jenis kegiatan sekaligus yaitu: 1) Kegiatan mengumpulkan dana dari berbagai sumber seperti: zakat, infaq dan shodaqoh serta lainya yang dibagikan/disalurkan kepada yang berhak dalam rangka mengatasi kemiskinan, dan 2) Kegiatan produktif dalam rangka nilai tambah baru dan mendorong pertumbuhan ekonomi yang bersumber daya manusia.

LKMS merupakan kelompok swadaya masyarakat sebagai lembaga ekonomi rakyat yang berupaya mengembangkan usaha-usaha produktif dan investasi dengan berdasar prinsip syariah untuk meningkatkan kualitas ekonomi pengusaha kecil dalam upaya pengentasan kemiskinan. Berdasarkan definisi tersebut dapat ditarik kesimpulan bahwa LKMS adalah suatu lembaga keuangan mikro yang menggabungkan unsur profit dan unsur nirlaba (sosial) dalam kegiatan usahanya yang dijalankan sesuai dengan ketentuan syariah.

Sifat usaha LKMS yang berorientasi pada bisnis dimaksudkan supaya pengelolaan LKMS dapat dijalankan secara profesional, sehingga mencapai tingkat efisiensi tertinggi. Dari sinilah LKMS akan mampu memberikan bagi hasil yang kompetitif kepada deposannya serta mampu meningkatkan kesejahteraan para pengelolanya sejajar dengan lembaga lainnya. Sedangkan aspek sosial LKMS berorientasi pada peningkatan kehidupan anggota dan masyarakat sekitar yang membutuhkan.

\section{Jenis Penelitian}

Metode yang digunakan dalam penelitian ini adalah deskriptif kualitatif berdasarkan data yang terkumpul melalui studi literatur, observasi dan kuesioner. Metode ini berusaha mendeskripsikan atau melukiskan secara terperinci model peningkatan kualitas SDM LKMS melalui sistem pengembangan. Dengan pemilihan rancangan deskriptif kualitatif, diinterpretasikan makna yang tersurat dan tersirat dari penjelasan yang diberikan responden melalui analisis deskriptif.

\section{Teknik Pengumpulan Data}

Data yang ingin diperoleh dalam penelitian terdiri dari data primer dan data 
sekunder. Adapun data primer diperoleh dari responden dengan menggunakan observasi dan wawancara mendalam. Wawancara mendalam akan dilaksanakan kepada tokoh kunci/jumlah terbatas dari responden. Data sekunder diperoleh dari literature-literatur yang terkait dengan kajian penelitian ini.

\section{Populasi dan Sampel}

Populasi penelitian adalah LKMS yang ada di Bogor terdiri dari BMT dan koperasi syariah. Sampling diambil secara purposive (purposive sampling), dimaksudkan agar sampel dapat memberikan informasi dalam menyusun model peningkatan kualitas SDM LKMS melalui sistem pengembangan. Di lokasi penelitian diambil 5 LKMS yang terdiri dari Koperasi Syariah dan BMT. Keseluruhan sampel berjumlah 5 (lima) LKMS.

\section{Teknik Analisis Data}

Untuk melakukan penelitian ini dilaksanakan beberapa kegiatan berikut:

1. Pengumpulan data SDM LKMS;

2. Pengumpulan data tentang faktorfaktor yang mempengaruhi kualitas SDM LKMS;

3. Pengumpulan data tentang peran LKMS dalam pelayanan keuangan bagi masyarakat;

4. Pengumpulan data tentang persepsi nasabah/masyarakat

terhadap pelayanan keuangan yang diberikan oleh SDM LKMS.

5. Pengumpulan data tentang sistem pengembangan SDM

6. Melakukan analisis situasi

7. Melakukan analisis data dan menyusun laporan penelitian

Adapun teknik analisis data yang digunakan seperti yang dikemukakan oleh Miles dan Huberman, mencakup tiga kegiatan yaitu :

1. Reduksi Data dimaksudkan untuk menajamkan, menggolongkan, mengarahkan, membuang yang tidak perlu, dan mengorganisasi sehingga interpretasi bisa ditarik
2. Penyajian Data merupakan sekumpulan informasi tersusun yang memberi kemungkinan untuk menarik kesimpulan dan pengambilan tindakan dengan tujuan untuk memudahkan membaca dan menarik kesimpulan.

3. Penarikan Kesimpulan/Verifikasi

Untuk lebih jelasnya teknik analisa data ini dapat dilihat pada gambar berikut :

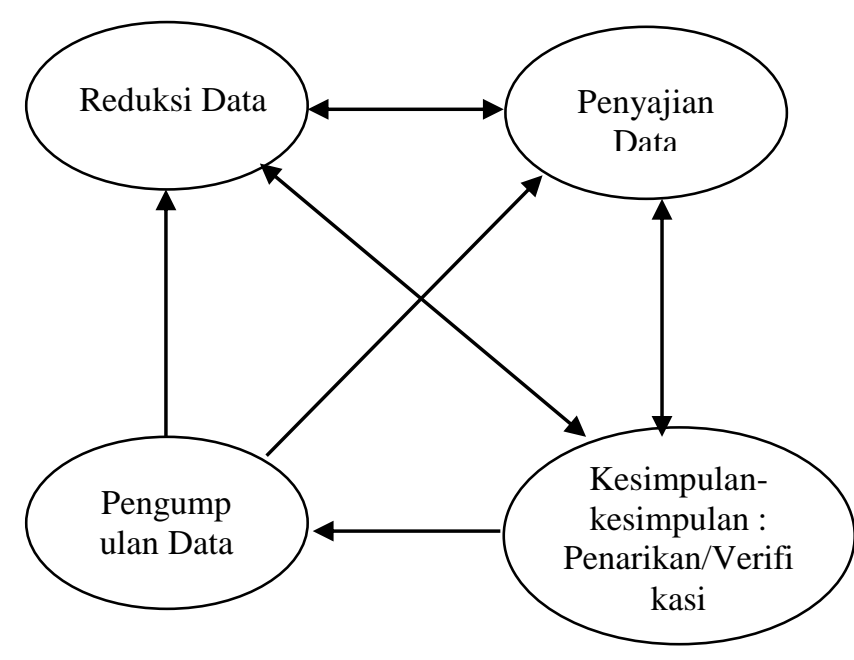

Gambar 1.

Analisis Data Model Interaktif

\section{HASIL DAN PEMBAHASAN}

\section{Gambaran Lembaga Keuangan Mikro Syariah di Bogor}

\section{BMT Berkah Mandiri Sejahtera}

Merujuk pada regulasi pemerintah pada awal tahun 2016, bahwa semua Koperasi Jasa Keuangan Syariah harus diganti dengan Koperasi Simpan Pinjam Pembiayaan Syariah. Maka dengan ketentuan tersebut "BMT BERKAH MANDIRI SEJAHTERA" harus berubah bentuk nama yang tadinya KJKS dirubah menjadi KSPPS. Seiring dengan perkembangan jaman pada awal tahun 2015 "KSPPS BMT" Berkah Mandiri Sejahtera sudah membuka kantor Unit Layanan di daerah Cariu Jonggol Kabupaten Bogor guna untuk memperluas pelayanan kepada masyarakat. Perkembangan dan pertumbuhan KSPPS BMT Berkah Mandiri Sejahtera dari tahun ke tahun terus meningkat karena mendapat 
dukungan dan kepercayaan dari berbagai pihak, diantaranya dukungan dan kepercayaan Anggota, dari Bank Syariah Mandiri, Bank Muamalat Indonesia, Diskoperindag (Pemerintah), dan Lembaga Keuangan Mikro lainnya serta dukungan beberapa organisasi seperti, Dekopinda, Puskopsyah dan Absindo.

Berdasarkan Undang-Undang Koperasi Nomor 25 Tahun 1992 dan peraturan pemerintah bahwa setiap bentuk koperasi harus memiliki badan hukum, maka bulan Juli tahun 2013 "KSPPS BMT BERKAH MANDIRI SEJAHTERA" yang beralamat di Jl. Raya Puncak Cisarua Ruko Blok C.II No. 11 A Desa Citeko Kecamatan Cisarua Kabupaten Bogor, resmi memiliki badan hukum dengan Nomor Badan Hukum: 518/314/BH/KPTS/DISKOPERINDAG/VII/ 2013, dan Surat Keputusan Kementrian Negara Koperasi dan Usaha Kecil dan Menengah Republik Indonesia. KSPPS BMT Berkah Mandiri Sejahtera memiliki basis kegiatan ekonomi kerakyatan dengan falsafah "Dari anggota, oleh anggota, dan untuk anggota" serta memiliki motto "Manfaat dan Maslahat untuk Ummat".

Jadi, secara prinsip ada perbedaan yang sangat mendasar antara koperasi konvensional (non syariah) dengan koperasi syariah, terletak pada teknis operasionalnya. Pada koperasi syariah mengharamkan bunga dan mengusung etika moral dengan melihat kaidah halal dan haram dalam melakukan usahanya.

2. KSPPS Berkah Bersama

Koperasi Simpan Pinjam dan Pembiayaan Syariah Berkah Bersama (KSPPS Berkah Bersama) merupakan sebuah lembaga yang bergerak di bidang jasa keuangan dan berbadan hukum koperasi, didirikan pada tanggal 8 Februari 2013 di Kota Bogor. Namun, cikal bakal sebelum diterbitkannya badan hukum telah berdiri pada tahun 2012. KSPPS Berkah Bersama ini awalnya bernama Koperasi Jasa Keuangan Syariah Berkah Bersama diganti menjadi KSPPS Berkah Bersama sesuai dengan peraturan dari menteri Koperasi. Awalnya berdiri KSPPS Berkah
Bersama ini berasal dari dua belas (12) founder yang memiliki tujuan, visi dan misi yang sama untuk membentuk sebuah lembaga keuangan syariah yang profesional dibidangnya dan dapat menyentuh kalangan usaha kecil dan menengah. Dengan modal awal Rp 50.000.000,- KSPPS Berkah Bersama melangsungkan usahanya yang bertempat di Jl. Meyjen Ishak Djuarsa No. 6 Kelurahan Loji Kota Bogor dengan karyawan yang berjumlah 5 orang. KSPPS Berkah Bersama memiliki dua kantor layanan yang bertempat di Caringin dan Leuwisadeng Kabupaten Bogor. Setelah tiga tahun berselang, KSPPS Berkah Bersama membentuk tiga kantor layanan yang bertempat di Serang, Cibinong, dan Gunung Batu. Kemudian membuka sebuah kantor layanan yang masih baru yang bertempat di Parung. Jadi, total kantor layanan cabang KSPPS Berkah Bersama berjumlah enam (6), dengan satu kantor pusat yang saat ini bertempat di Jalan Baru Yasmin Kabupaten Bogor.

\section{KSPPS BMT Binaul Ummah}

KSPPS BMT Binaul Ummah, selama ini berkiprah dalam upaya memberdayakan ekonomi kecil dengan menerapkan sistem ekonomi syariah. Dalam perjalanannya keberadaan KSPPS BMT Binaul Ummah besar sekali manfaat yang bisa dirasakan oleh masyarakat, terutama para pengusaha kecil yang berada di wilayah kota dan kabupaten Bogor. Tahun 2016 merupakan tahun kerja yang tidak jauh berbeda dari tahun sebelumnya, dimana prestasi kerja KSPPS BMT BUM belum mengalami peningkatan yang signifikan dari sisi finansial, yang dapat dilakukan masih dalam upaya bagaimana agar lembaga keuangan mikro syariah ini tetap eksis dalam pemberdayaan ekonomi masyarakat, ditengah banyaknya lembaga-lembaga pesaing yang lebih berpengalaman dan lebih profesional dalam melakukan bisnis sektor micro finance ini. Disamping itu pada tahun 2016 ini banyak sekali tantangan yang dihadapi, salah satu tantangan yaitu sulitnya mengakses dana 
perbankan dalam upaya menambah modal kerja KSPPS BMT BUM. Padahal perbankan biasanya menjadi alternatif sumber pendanaan bagi KSPPS BMT BUM, namun tahun 2016 untuk mengakses dana ke perbankan begitu sulit mereka memberlakukan beberapa persyaratan yang tidak mungkin KSPPS BMT BUM bisa memenuhinya. Tidak seperti pada tahuntahun sebelumnya persyaratan yang diminta cukup mudah untuk dipenuhi. Namun demikian KSPPS BMT Binaul Ummah selama tahun 2016 masih tetap bisa mempertahankan eksistensinya, padahal dilain pihak banyak lembagalembaga keuangan yang mengalami kesulitan dalam mempertahankan eksistensi lembaganya, dan tidak sedikit yang mengalami collapse bahkan sampai bangkrut. Akan tetapi, sampai saat ini BMT Binaul Ummah masih tetap bisa melayani kebutuhan anggotanya. Hal ini disebabkan oleh dukungan dan do'a dari semua pihak yang tetap bekerjasama dengan KSPPS BMT Binaul Ummah. Meskipun selama tahun 2016 KSPPS BMT Binaul Ummah belum mengalami peningkatan prestasi yang signifikan dari sisi kinerjanya, akan tetapi ada satu hal yang membanggakan KSPPS BMT Binaul Ummah, dimana pada tahun ini pengurus KSPPS BMT Binaul Ummah dapat mewujudkan harapan yaitu memiliki gedung kantor operasional milik sendiri yang cukup representatif. Hal ini cukup memberikan dorongan, ketenangan dan kenyamanan semua Sumber Daya Manusia (SDM) KSPPS BMT Binaul Ummah dalam bekerja. Selain itu KSPPS BMT Binaul Ummah di tahun 2016 juga ditetapkan sebagai Koperasi berprestasi tingkat Kota Bogor dengan SK Walikota Nomor 518.45149 tahun 2016.

\section{KBMT Tadbitul Ummah}

KBMT Tadbiirul Ummah, pertama kali didirikan sebagai Lembaga Pemberdayaan Masyarakat di daerah Ds. Babakan, Kec. Dramaga, Bogor atas inisiatif beberapa mahasiswa IPB (Institut Pertanian Bogor). Berjalan dengan berkembangnya layanan maka dibentuklah BMT (Baytul Maal wat
Tamwil) dengan dibantu oleh yayasan PERAMU (Pemberdayaan Mustadhaffin) sebagai pendamping dan inisiator pada tanggal 20 Desember 1995. Pada tanggal 08 Agustus 1998, BMT Tadbiirul Ummah mendapatkan izin operasi sebagai Koperasi dengan No. Badan Hukum: 05/BH/KDK.105/VIII/1998 dengan jumlah anggota 20 orang dan modal disetor sebesar Rp. 9 juta, dan menjadi KBMT Tadbiirul Ummah. Pada tahun 2015 sesuai dengan Peraturan Menteri semua koperasi yang menjalankan kegiatan simpan, pinjam dan pembiayaan dengan pola syariah harus berubah menjadi KSPPS (Koperasi Simpan Pinjam dan Pembiayaan). Pada akhir tahun 2015, jumlah modal yang berhasil dibukukkan sebesar Rp. 603 juta, dengan total asset sebesar Rp. 13,5 milyar. Total anggota/mitra layanan (pembiayaan dan penyimpan dana aktif) kurang lebih 3.500 orang. Saat ini KBMT Tadbiirul Ummah melayani 7 kecamatan yang tersebar di Kabupaten/Kota Bogor, yaitu: Dramaga, Ciampea, Tenjolaya, Ciomas, Babakan Madang, Sukaraja, Cibinong, dan Kota Bogor. Pasar tradisional yang dijangkau meliputi Pasar Anyar, Pasar Ciampea, Pasar Induk Kemang Bogor, Pasar Ciluar dan beberapa wilayah perdagangan disekitar Kampus IPB Dramaga.

5. Koperasi Baitul Ikhtiar (BAIK)

Koperasi Baitul Ikhtiar (BAIK) merupakan salah satu Lembaga Keuangan Mikro Syariah yang berada di bawah naungan Yayasan Pengembangan Masyarakat Mustadh'affin (Peramu). Koperasi Baitul Ikhtiar resmi berdiri sebagai koperasi berbadan hukum pada tahun 2008. Sebelum berbadan hukum koperasi, organisasi ini memulai aktivitasnya dengan melakukan program pemberdayaan masyarakat miskin melalui Unit Pelayanan Keuangan (UPK) Ikhtiar. Program ini dimulai pada tahun 1991 di wilayah pedesaan Kecamatan Tamansari dan berkembang dikawasan miskin perkotaan Bogor pada tahun 2002. Pada tahun 2003, pelayanan UPK Ikhtiar dapat digunakan sebagai proses pembentukan 
kelompok pedagang sayuran di pasar jambu dua kota Bogor. Tujuannya adalah untuk membangun kapasitas sosial dan ekonomi keluarga berpenghasilan rendah agar memiliki kemampuan dalam memenuhi kebutuhan dasar melalui pengelolaan asset ekonomi rumah tangga. Adapun wilayah jangkauan pembiayaan Koperasi Baitul Ikhtiar (BAIK) telah tersebar diberbagai kecamatan di Kota Bogor, Kabupaten Bogor, dan Kabupaten Sukabumi. Hingga saat ini, Koperasi Baitul Ikhtiar (BAIK) melakukan aktifitas pemberdayaan berbasis komunitas melalui pelayanan keuangan mikro. Pemberdayaan ini merupakan replika dari pola grameen bank yang melakukan pendekatan secara kelompok yang ditujukan secara khusus bagi kaum perempuan dari keluarga berpenghasilan rendah.

\section{Sistem Pengembangan SDM LKMS di Bogor}

Secara umum, sistem pengembangan SDM yang dilakukan oleh masing-masing 5 LKMS di Bogor tergambarkan melalui tiga elemen, yaitu rekrutmen, pendidikan dan pelatihan, serta promosi jabatan. Rekrutmen dilaksanakan berdasarkan kebutuhan dari masing-masing LKMS terhadap pemenuhan kinerja. Akan tetapi, pada tahap pelaksanaannya tetap berdasarkan pada standar operasional prosedur dan standar operasional manajemen masing-masing LKMS.

SDM yang telah memenuhi kriteria LKMS dan diterima sebagai SDM baru memerlukan peningkatan pengetahuan dan keterampilan yang dimiliki masing-masing SDM yaitu dengan melakukan pendidikan dan latihan. Pendidikan dan latihan ini menjadi faktor utama dalam meningkatkan kualitas SDM. Diantara bentuk pendidikan dan latihan tersebut adalah berupa pelatihan pengenalan produk bagi karyawan baru, pelatihan marketing, serta seminar-seminar lain yang mampu meningkatkan kemampuan SDM.

Setiap LKMS sangat mengapresiasi karyawannya dan masing-masing memiliki hak yang sama untuk meningkatkan jenjang karirnya. SDM yang kinerjanya sesuai dan melebihi target yang ditentukan, memiliki peluang besar untuk meningkat karirnya. Bahkan terdapat kemungkinan karyawan dipromosikan jabatan oleh pihak pimpinan. Tetapi, promosi jabatan tersebut berdasarkan atas aspek-aspek penilaian dari pihak internal maupun eksternal. Pihak internal memandang karyawan yang dipromosikan tersebut memiliki kemampuan dan keahlian dalam memenuhi target-target yang diberikan, sikap dalam memberikan pelayanan kepada para nasabah, kedisiplinan, serta kejujuran masing-masing karyawan.

\section{Sistem Pengembangan SDM di BMT Berkah Mandiri Sejahtera}

Untuk mengembangkan potensi yang dimiliki para karyawan, BMT Berkah Mandiri Sejahtera memberikan berbagai pendidikan dan pelatihan, karena pada dasarnya setiap karyawan diisyaratkan memiliki keterampilan atau kemampuan yang sesuai dengan keperluan untuk melaksanakan pekerjaannya, pelatihan dan pendidikan tersebut akan dilakukan untuk memenuhi kebutuhan operasi BMT Berkah Mandiri Sejahtera.

Dalam pelatihan Sumber Daya Insani ini BMT Berkah Mandiri Sejahtera melakukan kerjasama dengan lembaga lain diantaranya Lembaga Diklat Profesi PINBUK, Lembaga Absindo, Lembaga LSP Perkoperasian Indonesia, Balai Pelatihan Koperasi dan Usaha Mikro Kecil Provinsi Jawa Barat, Dinas Koperasi UKM Perindustrian dan Perdagangan, DEKOPINDA. Karyawan pada BMT Berkah Mandiri Sejahtera dididik juga untuk memiliki keterampilan berkomunikasi dan aspiratif, hal ini bertujuan dalam konsep untuk membangun keahlian atau kemampuan dari masing-masing Sumber Daya Manusia (SDM) pada BMT Berkah Mandiri Sejahtera. Adapun laporan kegiatan pengembangan Sumber Daya Manusia (SDM) di BMT Berkah Mandiri Sejahtera pada tahun 2015-2016 yaitu: 
Tabel 1

Laporan Realisasi kegiatan pelatihan Sumber Daya Insani Pada BMT Berkah Mandiri Sejahtera

\begin{tabular}{|c|c|c|c|c|}
\hline No & $\begin{array}{l}\text { Jenis } \\
\text { Pendidikan } \\
\text { \& Pelatihan }\end{array}$ & $\begin{array}{c}\text { Penyelengga } \\
\text { ra Diklat }\end{array}$ & $\begin{array}{c}\text { Waktu } \\
\text { Pelaksana } \\
\text { an }\end{array}$ & $\begin{array}{c}\text { Jumlah } \\
\text { Peserta } \\
\text { yang } \\
\text { diserta } \\
\text { kan } \\
\end{array}$ \\
\hline 1. & $\begin{array}{c}\text { Sistem } \\
\text { Akuntansi } \\
\text { Terintegrasi }\end{array}$ & $\begin{array}{c}\text { Dinas } \\
\text { Koperasi, } \\
\text { UKM, } \\
\text { Perindustrian } \\
\text { dan } \\
\text { Perdagangan }\end{array}$ & $\begin{array}{c}\text { November, } \\
2014\end{array}$ & $\begin{array}{c}\text { Manajer } \\
\text { dan } \\
\text { Bagian } \\
\text { Adm \& } \\
\text { Keuanga } \\
\text { n (2 } \\
\text { orang) }\end{array}$ \\
\hline 2. & $\begin{array}{l}\text { Fundamental } \\
\text { Spiritual } \\
\text { \&Motivation }\end{array}$ & $\begin{array}{c}\text { LPM } \\
\text { Universitas } \\
\text { Tazkia dan } \\
\text { Takaful }\end{array}$ & $\begin{array}{c}\text { Februari, } \\
2015\end{array}$ & $\begin{array}{c}\text { Manajer } \\
\text { \&Accou } \\
\text { nt Oficer } \\
\text { (2 } \\
\text { orang) }\end{array}$ \\
\hline 3. & $\begin{array}{c}\text { BIMTEK } \\
\text { ADMINISTRA } \\
\text { SI } \\
\text { ORGANISASI } \\
\text { KOPERASI }\end{array}$ & $\begin{array}{c}\text { Dinas } \\
\text { Koperasi, } \\
\text { UKM, } \\
\text { Perindustrian } \\
\text { dan } \\
\text { Perdagangan }\end{array}$ & $\begin{array}{l}\text { Maret, } \\
2015\end{array}$ & $\begin{array}{c}\text { Manajer } \\
\text { dan } \\
\text { Bagian } \\
\text { Adm \& } \\
\text { Keuanga } \\
\text { n (2 } \\
\text { orang) } \\
\end{array}$ \\
\hline 4. & $\begin{array}{c}\text { Sertifikasi } \\
\text { Kompetensi } \\
\text { Manajer }\end{array}$ & $\begin{array}{c}\text { Dinas } \\
\text { Koperasi, } \\
\text { UKM, } \\
\text { Perindustrian } \\
\text { dan } \\
\text { Perdagangan } \\
\end{array}$ & Mei, 2015 & $\begin{array}{c}\text { Ketua } \\
\text { Penguru } \\
\text { s dan } \\
\text { Manajer } \\
\text { (2 } \\
\text { orang) }\end{array}$ \\
\hline 5. & $\begin{array}{c}\text { Pengelola } \\
\text { Lembaga } \\
\text { Keuangan } \\
\text { Mikro } \\
\text { Syariah } \\
\end{array}$ & $\begin{array}{c}\text { LPM } \\
\text { Universitas } \\
\text { Tazkia }\end{array}$ & $\begin{array}{c}\text { November, } \\
2015\end{array}$ & $\begin{array}{l}\text { Manajer } \\
\text { dan } \\
\text { Account } \\
\text { Officer(2 } \\
\text { orang) }\end{array}$ \\
\hline 6. & $\begin{array}{c}\text { Study } \\
\text { Banding ke } \\
\text { KOPKAR } \\
\text { Subang }\end{array}$ & $\begin{array}{c}\text { PUSKOPSYAH } \\
\text { dan Dinas } \\
\text { Koperasi }\end{array}$ & $\begin{array}{l}\text { Februari, } \\
2016\end{array}$ & $\begin{array}{l}\text { Manajer } \\
\text { dan } \\
\text { Account } \\
\text { Officer(2 } \\
\text { orang) }\end{array}$ \\
\hline
\end{tabular}

Sumber: Data BMT Berkah Mandiri Sejahtera, 2016

\section{KSPPS Berkah Bersama}

Sistem pengembangan pada KSPPS Berkah Bersama dilaksanakan kegiatan meeting, dalam kegiatan meeting ini pimpinan membangun pemahaman visi, misi , dan tujuan. Serta mendorong setiap karyawan untuk melakukan pertukaran gagasan dan informasi. Dilakukan kegiatan ini sebenarnya merupakan bentuk apresiasi dari pihak manajer kepada karyawan KSPPS Berkah Bersama.

KSPPS Berkah Bersama Cabang Caringin memiliki program pelatihan yang bertujuan untuk mengembangkan keterampilan dan pengetahuan diantaranya program hari mutu. Kegiatan hari mutu adalah kegiatan seperti briefing, kegiatan ini memberikan materi kepada semua Sumber Daya Insani KSPPS Berkah Bersama Cabang Caringin tentang ekonomi Islam secara umum, perbankan syariah, ilmu ekonomi. KSPPS Berkah Bersama selalu melakukan pembinaan sumber daya manusia (SDM) setiap minggunya. Hal ini dilakukan untuk menambah wawasan karyawan.

Pelatihan dan pengembangan Sumber Daya Manusia pada sebuah lembaga keuangan sangat erat hubungannya dengan hasil kinerja kerja dari masing-masing karyawan. Oleh karena itu, dibutuhkan sebuah penilaian untuk mengukur kinerja dan pelatihan Sumber Daya Manusia (SDM) pada KSPPS Berkah Bersama. Pelatihan karyawan KSPPS Berkah Bersama dilakukan dengan tujuan agar para karyawan memiliki pengetahuan, kemampuan dan keterampilan sesuai dengan tuntutan pekerjaan.

Pelatihan di KSPPS Berkah Bersama adalah suatu upaya untuk meningkatkan atau menambah pengetahuan dan skill karyawan. Setiap pelatihan wajib diikuti oleh karyawan, baik karyawan baru maupun karyawan lama. Bagi karyawan baru wajib mengikuti on the job training, yaitu pelatihan yang berbentuk penugasan karyawan-karyawan yang telah berpengalaman untuk membimbing atau mengajarkan kepada karyawan baru. Pelatihan ini berlangsung selama tiga bulan.

\section{BMT Binaul Ummah}

Upaya BMT Binaul Ummah untuk mengembangkan potensi yang dimiliki karyawan, BMT Binaul Ummah memberikan berbagai pelatihan diantaranya pelatihan internal dan pelatihan eksternal. Pelatihan internal yang diadakan BMT Binaul Ummah yaitu pelatihan kerja sehari-hari dan memberikan arahan-arahan tentang keterampilan dan keahlian oleh manajemen. Pelatihan internal yang dilakukan tidak resmi menjadi sebuah pelatihan yang seharusnya diselenggarakan. Untuk pelatihan eksternal bersifat resmi diprogramkan dan diadakan 
oleh pemerintah serta lembaga-lembaga swasta lain. Dalam pelatihan Sumber Daya Manusia (SDM) ini BMT Binaul Ummah melakukan kerjasama dengan lembaga lain diantaranya Lembaga Diklat Profesi PINBUK, Dinas Koperasi dan Pemerintah. Disamping pelatihan ditujukan untuk karyawan adapun pelatihan bagi pengurus BMT Binaul Ummah. BMT Binaul Ummah mengikutsertakan semua karyawan, pengurus dan pengelola dalam kegiatan program pelatihan yang diadakan oleh pihak eksternal oleh dinas koperasi maupun oleh pemerintah. Adapun laporan kegiatan pelatihan dan kegiatan workshop yang diikuti oleh Sumber Daya Manusia (SDM) BMT Binaul Ummah pada tahun 2016 yaitu:

Tabel 2

Laporan Realisasi kegiatan pelatihan Sumber Daya Insani pada BMT Binaul Ummah

\begin{tabular}{|l|l|l|l|l|}
\hline No & $\begin{array}{c}\text { Nama } \\
\text { Kegiatan } \\
\text { Pelatihan }\end{array}$ & $\begin{array}{l}\text { Penyeleng } \\
\text { gara } \\
\text { Pelatihan }\end{array}$ & $\begin{array}{c}\text { Waktu } \\
\text { Pelaksa } \\
\text { naan } \\
\text { Pelatiha } \\
\text { n }\end{array}$ & Peserta \\
\hline 1 & $\begin{array}{l}\text { Teknik } \\
\text { Internal } \\
\text { Audit }\end{array}$ & $\begin{array}{l}\text { ABSINDO } \\
\text { Sukabumi }\end{array}$ & $\begin{array}{l}\text { Februari } \\
, 2016\end{array}$ & $\begin{array}{l}\text { Zuhrotul } \\
\text { Winiah }\end{array}$ \\
\hline 2 & $\begin{array}{l}\text { Studi } \\
\text { Banding ke } \\
\text { KOPKAR }\end{array}$ & $\begin{array}{l}\text { PUSKOPSY } \\
\text { AH, Dinas } \\
\text { Koperasi }\end{array}$ & $\begin{array}{l}\text { Februari } \\
, 2016\end{array}$ & $\begin{array}{l}\text { Agus } \\
\text { Pranamul } \\
\text { ia }\end{array}$ \\
\hline 3 & $\begin{array}{l}\text { PelatihanT } \\
\text { ax Amnesty } \\
\text { dan pajak }\end{array}$ & $\begin{array}{l}\text { Dekopinda } \\
\text { Kota Bogor }\end{array}$ & $\begin{array}{l}\text { Septemb } \\
\text { er, 2016 }\end{array}$ & $\begin{array}{l}\text { Zuhrotul } \\
\text { Winiah }\end{array}$ \\
\hline 4 & $\begin{array}{l}\text { Pelatihan } \\
\text { Pengawas } \\
\text { Koperasi }\end{array}$ & $\begin{array}{l}\text { Kementria } \\
\text { n KUMKM } \\
\text { RI \& DSN }\end{array}$ & $\begin{array}{l}\text { Septemb } \\
\text { er, 2016 }\end{array}$ & $\begin{array}{l}\text { Agus } \\
\text { Pranamul } \\
\text { ia }\end{array}$ \\
\hline
\end{tabular}

Sumber : Data BMT Binaul Ummah, 2016

Sumber Daya Manusia (SDM) di Binaul Ummah diharuskan meningkatkan pengetahuannya dengan mengikuti program pendidikan dan pelatihan. Sebagai tenaga profesional dituntut selalu meningkatkan pengetahuannya, dengan meningkatkan tingkat pendidikan yang lebih tinggi.

\section{KBMT Tadbiirul Ummah}

Sistem pengembangan yang dilaksanakan di KBMT Tadbiirul Ummah adalah sebagai berikut :

1) Rekrutmen
2) Pembinaan karir, reward, dan punishment karyawan.

Pelatihan yang diberikan kepada semua karyawan KBMT Tadbiirul Ummah adalah pelatihan keterampilan dan pelatihan motivasi. Pelatihan keterampilan yang diberikan adalah sebuah pelatihan mengenai pengenalan dan pendalaman keterampilan seseorang baik secara teknis (hard skill) maupun bersifat pengembangan pribadi (soft skill). Pelatihan ini bertujuan untuk menambah pengetahuan maupun skill karyawan. Yang termasuk pelatihan keterampilan adalah :

1) Pelatihan Teller

2) Pelatihan Accounting

3) Pelatihan Team Marketing

4) Pelatihan manajemen

Terdapat program pelatihan yang bertujuan mengembangkan keterampilan dan pengetahuan Sumber Daya Insani KBMT Tadbiirul Ummah diantaranya program yang dilakukan setiap hari sabtu yaitu in house training.

\section{Koperasi Baitul Ikhtiar (BAIK)}

Pelatihan yang diberikan kepada semua karyawan Koperasi Baitul Ikhtiar bertujuan untuk meningkatkan wawasan pengurus koperasi untuk mengelola koperasi sesuai praktik bisnis yang sehat, meningkatkan kemampuan pengurus atau pengelola dalam hal bekerja, meningkatkan wawasan karyawan dalam menjalankan usaha koperasi dengan efektif dan efisien, meningkatkan keterampilan karyawan dibidang akuntansi koperasi sehingga mampu mengerjakan administrasi keuangan sesuai sistem akuntansi koperasi. Dalam kegiatan pelatihan karyawan, Koperasi Baitul Ikhtiar (BAIK) juga bekerjasama dengan lembaga lain diantaranya Dinas Koperasi, BUS, BPRS, Koperasi, LAZ, NGO, Yayasan/Lembaga pendidikan, Lembaga Pelatihan dan sertifikasi. 
Tabel 3

\section{Realisasi kegiatan pelatihan Sumber Daya Insani pada Koperasi Baitul} Ikhtiar (BAIK)

\begin{tabular}{|c|c|c|c|c|}
\hline No. & $\begin{array}{c}\text { Nama } \\
\text { Kegiatan }\end{array}$ & Lokasi & $\begin{array}{c}\text { Pesert } \\
\text { a }\end{array}$ & $\begin{array}{c}\text { Penyelen } \\
\text { ggara }\end{array}$ \\
\hline 1. & $\begin{array}{l}\text { Evaluasi } \\
\text { Bulanan }\end{array}$ & $\begin{array}{l}\text { Kantor } \\
\text { Cabang } \\
\text { Kota }\end{array}$ & $\begin{array}{l}\text { All staff } \\
\text { Cabang }\end{array}$ & Cabang \\
\hline 2. & $\begin{array}{l}\text { Muhasab } \\
\text { ah }\end{array}$ & $\begin{array}{l}\text { Aula SMK } \\
\text { Nusa } \\
\text { Bangsa }\end{array}$ & $\begin{array}{l}\text { All staff } \\
\text { Cabang }\end{array}$ & $\begin{array}{l}\text { KSPPS- } \\
\text { Baik }\end{array}$ \\
\hline 3. & $\begin{array}{l}\text { Parenting } \\
: \quad \text { Pola } \\
\text { Asuh } \\
\text { Anak } \\
\text { Berbasis } \\
\text { Karakter }\end{array}$ & $\begin{array}{l}\text { Wisma } \\
\text { Gizi, } \\
\text { Semeru }\end{array}$ & $\begin{array}{l}\text { Ka. } \\
\text { Cab- } \\
\text { SPV }\end{array}$ & $\begin{array}{l}\text { Indonesia } \\
\text { Heritage } \\
\text { Foundatio } \\
n\end{array}$ \\
\hline 4. & $\begin{array}{l}\text { Pelatihan } \\
\text { akad }\end{array}$ & $\begin{array}{l}\text { Kantor } \\
\text { Cabang } \\
\text { Kota }\end{array}$ & $\begin{array}{l}\text { All staff } \\
\text { Cabang }\end{array}$ & Maulana \\
\hline 5. & R.A.T & $\begin{array}{l}\text { Gd. } \\
\text { Suryaken } \\
\text { cana }\end{array}$ & $\begin{array}{l}\text { Ka. } \\
\text { Cab- } \\
\text { SPV }\end{array}$ & $\begin{array}{l}\text { KSPPS- } \\
\text { Baik }\end{array}$ \\
\hline 6. & $\begin{array}{l}\text { Qur'anic } \\
\text { Parenting }\end{array}$ & $\begin{array}{l}\text { IPB } \\
\text { Dramaga }\end{array}$ & $\begin{array}{l}\text { Ka. } \\
\text { Cab- } \\
\text { SPV }\end{array}$ & $\begin{array}{l}\text { An-Naba } \\
\text { Tahfidz } \\
\text { School }\end{array}$ \\
\hline 7 & $\begin{array}{l}\text { TOT Pola } \\
\text { Hidup } \\
\text { Bersih \& } \\
\text { Sehat }\end{array}$ & $\begin{array}{l}\text { Gd. } \\
\text { Balitbang, } \\
\text { Balitro } \\
\text { Cimanggu }\end{array}$ & $\begin{array}{l}\text { Ka. } \\
\text { Cab- } \\
\text { SPV }\end{array}$ & $\begin{array}{l}\text { Team } \\
\text { Wash }\end{array}$ \\
\hline 8 & $\begin{array}{l}\text { If'thor } \\
\text { Jama'i }\end{array}$ & $\begin{array}{l}\text { Kantor } \\
\text { Cabang } \\
\text { Tamansar } \\
\text { i }\end{array}$ & $\begin{array}{l}\text { All staff } \\
\text { Cabang }\end{array}$ & $\begin{array}{l}\text { Kota } \\
\text { Dramaga- } \\
\text { Tamsar }\end{array}$ \\
\hline 9 & $\begin{array}{l}\text { I'tikaf } \\
\text { Jama'i }\end{array}$ & $\begin{array}{l}\text { Mesjid } \\
\text { Daar At- } \\
\text { Taubah } \\
\text { Tamansar } \\
\text { i }\end{array}$ & $\begin{array}{l}\text { All staff } \\
\text { Cabang }\end{array}$ & $\begin{array}{l}\text { KSPPS- } \\
\text { Baik }\end{array}$ \\
\hline 10 & $\begin{array}{l}\text { Piloting } \\
\text { TOT } \\
\text { Sosialisas } \\
\text { i PHBS }\end{array}$ & $\begin{array}{l}\text { Kantor } \\
\text { Cabang } \\
\text { Ciampea }\end{array}$ & $\begin{array}{l}\text { Ka. } \\
\text { Cab- } \\
\text { SPV }\end{array}$ & $\begin{array}{l}\text { Ka. Cab } \\
\text { KSPPS- } \\
\text { Baik }\end{array}$ \\
\hline 11 & $\begin{array}{l}\text { Pelatihan } \\
\text { akad } \\
\text { syariah }\end{array}$ & $\begin{array}{l}\text { Gd. } \\
\text { Balitbang, } \\
\text { Balitro } \\
\text { Cimanggu }\end{array}$ & $\begin{array}{l}\text { All staff } \\
\text { Cabang }\end{array}$ & $\begin{array}{l}\text { BPRS } \\
\text { Amanah } \\
\text { Ummah }\end{array}$ \\
\hline
\end{tabular}

Sumber : Data Koperasi Baytul Ikhtiar, 2016

\section{KESIMPULAN DAN IMPLIKASI}

Berdasarkan uraian hasil analisis dan pembahasan yang telah dipaparkan, maka dapat disimpulkan bahwa Lembaga Keuangan Mikro Syariah melaksanakan sistem pengembangan Sumber Daya Manusia melalui program pendidikan dan pelatihan, bak yang dilaksanakan di lingkungan pekerjaan (internal) ataupun di luar lingkungan pekerjaan (eksternal). Program pendidikan dan pelatihan dimaksudkan untuk mengembangkan SDM di LKMS, baik dari segi keterampilan maupun pengetahuan serta agama.

Sistem pengembangan yang dilaksanakan melalui program pendidikan dan pelatihan agar lebih diarahkan pada tingkat pencapaian kompetensi SDM sehingga LKMS lebih berkembang dan kinerjanya semakin meningkat.

\section{DAFTAR PUSTAKA}

Basrowi dan Suwandi, 2008. Memahami Penelitian Kualitatif. Rineka Cipta. Jakarta

Djuwarijah, 2008, Strategi Peningkatan Manajemen Kurikulum Dalam Pengembangan Mutu SDM Menuju Terwujudnya Lulusan Madrasah Aliyah berwawasan Internasional, Jurnal El Tarbawi Vol. 1 No.1.

Edi Saputra Pakpahan, Siswidiyanto dan Sukanto, 2008, Pengaruh Pendidikan dan Pelatihan terhadap Kinerja Pegawai, Jurnal Administrasi Publik, Vol. 2 No. 1.

Muhammad, 2009. Lembaga Keuangan Mikro Syariah Pergulatan Melawan Kemiskinan dan penetrasi Ekonomi Global. Graha Ilmu, Yogyakarta.

Notoatmojo, Soekidjo. 2003. Pengembangan Sumber Daya Manusia, Rineka Cipta, Jakarta.

Purnamasari, Irma. 2014. Model Peningkatan Kinerja Sumber Daya Aparatur Negara Melalui Sistem Pengadaan Pegawai Berbasis Kompetensi Di Lingkungan Pemerintah Daerah Kota Bogor. (Laporan Penelitian Hibah Pemula)

Raharjo, Dawam. 1999. Intelektual, Intelegensia dan Perilaku Politik Bangsa. Mizan. Bandung. 
Rivai, Veithzal. 2009. Islamic Human Capital, Dari Teori ke Praktek. PT. Raja Grafindo Persada. Jakarta.
Salam Dz, Abdus, 2014, Manajemen Insani Dalam Bisnis, Pustaka Pelajar, Yogyakarta. 